OPEN ACCESS

Edited by:

Aimin Xu,

The University of Hong Kong,

Hong Kong

Reviewed by:

Qiong Wang,

University of Texas Southwestern Medical Center, United States

Jongsook Kemper,

University of Illinois at Urbana-

Champaign, United States

${ }^{*}$ Correspondence:

Jae Bum Kim

jaebkim@snu.ac.kr

Specialty section:

This article was submitted to Immunological Tolerance and Regulation,

a section of the journal

Frontiers in Immunology

Received: 26 August 2020 Accepted: 10 December 2020

Published: 28 January 2021

Citation:

Park J, Sohn JH, Han SM, Park YJ, Huh JY, Choe SS and Kim JB (2021) Adipocytes Are the Control Tower That Manages Adipose Tissue Immunity by Regulating Lipid Metabolism.

Front. Immunol. 11:598566. doi: 10.3389/fimmu.2020.598566

\section{Adipocytes Are the Control Tower That Manages Adipose Tissue Immunity by Regulating Lipid Metabolism}

\author{
Jeu Park ${ }^{1,2,3}$, Jee Hyung Sohn ${ }^{1,2,3}$, Sang Mun Han ${ }^{1,2,3}$, Yoon Jeong Park ${ }^{1,2,3}$, \\ Jin Young Huh ${ }^{1,2,3}$, Sung Sik Choe ${ }^{1,2,3}$ and Jae Bum Kim ${ }^{1,2,3 *}$
}

\begin{abstract}
${ }^{1}$ National Creative Research Initiatives Center for Adipocyte Structure and Function, Seoul National University, Seoul, South Korea, 2 Institute of Molecular Biology and Genetics, Seoul National University, Seoul, South Korea, ${ }^{3}$ School of Biological Sciences, Seoul National University, Seoul, South Korea
\end{abstract}

Accumulating evidence reveals that adipose tissue is an immunologically active organ that exerts multiple impacts on the regulation of systemic energy metabolism. Adipose tissue immunity is modulated by the interactions between adipocytes and various immune cells. Nevertheless, the underlying mechanisms that control inter-cellular interactions between adipocytes and immune cells in adipose tissue have not been thoroughly elucidated. Recently, it has been demonstrated that adipocytes utilize lipid metabolites as a key mediator to initiate and mediate diverse adipose tissue immune responses. Adipocytes present lipid antigens and secrete lipid metabolites to determine adipose immune tones. In addition, the interactions between adipocytes and adipose immune cells are engaged in the control of adipocyte fate and functions upon metabolic stimuli. In this review, we discuss an integrated view of how adipocytes communicate with adipose immune cells using lipid metabolites. Also, we briefly discuss the newly discovered roles of adipose stem cells in the regulation of adipose tissue immunity.

Keywords: adipocytes, lipid metabolite, invariant natural killer cell, adipose tissue remodeling, adipose tissue inflammation

Abbreviation: $\alpha$-GC, Alpha-galactosylceramide; APC, Antigen presenting cell; ASC, Adipose stem cell; ATM, Adipose tissue macrophage; CD1dAKO, Adipocyte-specific CD1d depletion; ChREBP, Carbohydrate response element binding protein; ER, Endoplasmic reticulum; FALC, Fat-associated lymphoid cluster; FFA, Free fatty acid; GABA, Gamma-aminobutyric acid; HFD, High-fat diet; HIV, Human immunodeficiency virus; IFN, Interferon; IKK $\beta$, IkB kinase; IL, Interleukin; ILC, Innate lymphoid cell; iNKT, Invariant natural killer T; KD, Ketogenic diet; KO, Knock out; LD, Lipid droplet; MAOA, Monoamine oxidase; NLRP3, NLR family pyrin domain containing 3; NO, Nitric oxide; PAHSA, Palmitic acid esters of hydroxy stearic acid; PGE2, Prostaglandin E2; Plin, Perilipin; scRNA-seq, Single cell RNA-sequencing; SREBP1c, Sterol regulatory elementbinding protein 1c; SVC, Stromal vascular cell; sWAT, Subcutaneous white adipose tissue; TCR, T cell receptor; TNF, Tumor necrosis factor; Treg, Regulatory T cell; VLDLR, Very-low-density-lipoprotein receptor; vWAT, Visceral white adipose tissue; WAT, White adipose tissue. 


\section{INTRODUCTION}

Adipose tissue is a specific type of loose connective tissues present in various anatomical locations. For energy homeostasis and survival, adipose tissue contributes to numerous physiological roles: it provides structural support and protective padding for major organs, it serves as an insulating layer that prevents cutaneous heat loss, it stores extra energy source for longer periods of fasting, and it is a dynamic endocrine system crucial in the regulation of energy homeostasis (1). Among the various cell types residing in adipose tissue, adipocytes are the major cell type that is specialized to synthesize and store large globules of fat (2). When energy level is low, adipocytes break down stored lipid metabolites into fatty acids and glycerol and release them into circulation, which are used for fuels in most organs. This function of adipocytes enables adipose tissue to function as the major energy reservoir. Moreover, adipocytes act as a key component of endocrine activity through secreting a variety of signaling molecules such as adipokines, lipokines, and exosomes (3). These adipocytederived factors are involved in the maintenance of systemic energy homeostasis through crosstalk with other tissues such as muscle, liver, and brain (2).

Adipose tissue harbors diverse innate and adaptive immune cells. Dynamic interactions between these innate and adaptive immune cells are closely associated with alterations of adipose tissue function and integrity upon metabolic changes (4-6). For example, adipose tissue immunity shifts toward proinflammatory state in response to chronic energy surplus such as obesity, leading to dysregulation of adipose tissue homeostasis (7-10). Among various adipose immune cells, adipose tissue macrophages (ATMs) occupy about $50 \%$ and are largely classified into pro-inflammatory M1-type and antiinflammatory M2-macrophages $(11,12)$. In obesity, M1-type macrophages are abundantly accumulated and secrete proinflammatory molecules such as tumor necrosis factor (TNF)$\alpha$, nitric oxide (NO), and interleukin (IL)-6 (13-15). In addition, neutrophil, Th1, Th17, CD8 T cells, and group 1 innate lymphoid cell (ILC1) secrete pro-inflammatory cytokines including interferon (IFN)- $\gamma$, IL-6, and IL-17 $(16,17)$. These pro-inflammatory molecules suppress insulin action in adipocytes by inhibiting phosphorylation of insulin receptor and insulin receptor substrate 1 , which provokes insulin resistance. On the other hand, there are numerous antiinflammatory immune cells that downregulate proinflammatory responses, improving insulin sensitivity in adipose tissue. Eosinophil, regulatory $\mathrm{T}$ cell (Treg), invariant natural killer T (iNKT), and group 2 innate lymphoid cell (ILC2) stimulate to polarize macrophages towards anti-inflammatory M2-type macrophages through secretion of Th2 type cytokines, including IL-4, IL-5, IL-10, and IL-13, attenuating adipose inflammatory responses and improving insulin sensitivity (11).

Recently, emerging evidence indicates that adipocyte-derived lipid metabolites would function as a crucial regulator of adipose tissue immunity (18-21). In obese adipocytes, aberrant lipid metabolism promotes lipid spillover, which activates NF- $\mathrm{KB}$ pathways in ATMs and consequently induces TNF- $\alpha$ secretion
(22). Also, dysregulation of lipokines and lipid antigens is manifested in dysfunctional adipocytes, which has been linked to changes in characteristics of adaptive immune cells in adipose tissue. It has been recently shown that adipocyte-derived lipid antigens could alter inter-cellular interactions between innate and adaptive immune cells, followed by alterations of function and fate of adipocytes (23). Despite the close association of lipid metabolism in adipocytes with adipose tissue immunity has been reported for over a decade, the molecular mediators and mechanisms linking adipocyte-derived lipid metabolites to adipose tissue immunity remain poorly understood. In previous reviews, the importance of the crosstalk between innate and adaptive immune cells in adipose tissue on energy metabolism has been well addressed $(1,11,12)$. Thus, in this review, we cover the processes by which adipocytes communicate with adipose immune cells using lipid metabolites. Furthermore, we discuss the new concept that adipocytes cooperate with adipose immune cells to protect adipose tissue integrity from metabolic stresses. In addition, we briefly propose the novel roles of adipocyte stem cells in the regulation of adipose tissue immunity.

\section{IMMUNOMODULATORY ROLES OF ADIPOCYTES USING LIPID ANTIGENS}

There are distinct types of immune cells that recognize lipid antigens. These immune cells, such as iNKT cells and $\gamma \delta$ T cells, rapidly respond to changes of lipid metabolism through sensing lipid antigens loaded on antigen presenting cells (APCs). It has been reported that iNKT cells and $\gamma \delta \mathrm{T}$ cells are abundantly present in adipose tissue and actively interact with adipocytes, contributing to the regulation of systemic energy metabolism (24-27). For example, in obesity, adipose iNKT cells are activated by adipocyte-derived lipid antigens and modulate the interaction between innate and adaptive immune cells $(24,28,29)$. Moreover, activation of iNKT cells by hypertrophic adipocytederived lipid antigens stimulates adipocyte turnover in obesity, contributing to adipose tissue remodeling (23). Similarly, $\gamma \delta \mathrm{T}$ cells regulate adipose tissue immune responses and adipocyte functions $(26,27,30)$. Given that $\gamma \delta \mathrm{T}$ cells recognize CD1loaded lipid antigens, it has been suggested that adipocytes would control $\gamma \delta \mathrm{T}$ cell activity $(31,32)$. In this section, we discuss detailed mechanisms by which adipocytes regulate adipose tissue immune cells via lipid antigen presentation.

\section{Lipid Antigen Presentation}

In adipose tissue, there are several APCs such as dendritic cells, macrophages, B cells, and adipocytes $(24,25,33)$. It has been demonstrated that adipocytes highly express MHC-I like protein, CD1d, and present lipid antigens $(24,34)$. CD1d belongs to the CD1 family with isoforms such as CD1a, CD1b, CD1c, and CD1e (35). CD1d is a transmembrane protein with two alpha-helices forming an antigen-presenting pocket above and a hydrophobic pocket below (28). This structure encapsulates hydrophobic portion of lipid antigens into the CD1d binding groove, and 
the polar portion of the antigen is exposed outside APCs to be recognized by $\mathrm{T}$ cell receptor (TCR) (28).

With an antigen-presenting molecule CD1d, adipocytes express high levels of lipid antigen loading and presentationassociated genes (28). There are two major pathways involved in antigen loading and presentation. The first one is endoplasmic reticulum (ER) and Golgi pathway, and the second one is endosomal and lysosomal pathway. In ER and Golgi pathway, the newly synthesized CD1d binds to $\beta 2$-microglobulin in ER, and lipid antigens are loaded onto CD1d in Golgi by chaperone proteins, including microsomal triglyceride transfer protein (36, 37). Then, CD1d enters the transport step and fuses with the membrane to be exposed to cell surface of APCs. In endosomal and lysosomal pathway, CD1d is internalized in the form of endosome from plasma membrane. Chaperone protein and lipid transport protein replace low-affinity lipid antigens with high affinity lipid antigens $(36,37)$.

Although the clue for lipid antigen source has been suggested in several studies (38-41), the identity of endogenous lipid antigens in adipocytes has not been clearly elucidated. In the blood, circulating lipid metabolites are potentially subjected to behave as lipid antigens through scavenger receptor and verylow-density-lipoprotein receptor (VLDLR) (42). In VLDLassociated apoprotein APOE-deficient mice, the number of iNKT cells is altered (40). Also, fatty acid amide hydrolase enhances the presentation of lipid antigens by facilitating transport of serum lipids into APCs (41).

\section{Anti-Inflammatory Roles of Adipocytes via Lipid Antigen Presentation}

The roles of CD1d in adipocytes have been investigated in genetically or diet-induced obesity models. Studies using adipocyte-specific CD1d knockout (CD1d ${ }^{\mathrm{AKO}}$ ) mice have shown that adipocytes are crucial for the regulation of adipose iNKT cell activity (Figure 1A) $(34,43)$. In CD1d ${ }^{\mathrm{AKO}}$ mice, the number of iNKT cells is decreased. Moreover, the levels of IL-4 secretion and FasL expression are downregulated in iNKT cells of CD1d ${ }^{\mathrm{AKO}}$ mice compared to wild type (WT) mice, leading to aggravation in adipose tissue inflammation and insulin resistance $(23,34)$. The interaction between adipocytes and iNKT cells has been also examined in $\mathrm{J} \alpha 18$ knockout (KO) mice and CD1d $\mathrm{KO}$ mice in which iNKT cells are deficient in whole body $(24,25)$. In the case of the above animal models lacking iNKT cells, body weight gain and adipocyte size are increased, and pro-inflammatory ATMs are more accumulated in obesity. Stimulation of iNKT cell activity by alpha-galactosylceramide ( $\alpha$-GC), a synthetic lipid antigen for iNKT cell and supplementation of iNKT cells into obese mice downregulate body weight gain and adipocyte size and upregulate secretion of anti-inflammatory adipokines. These metabolic changes are accompanied with restoration of insulin sensitivity $(23,25)$.

One of the major regulatory mechanisms for adipose tissue inflammation by adipose iNKT cell is through diverse cytokine secretion. For instance, adipose iNKT cells secrete IL-4 and IL-10 which promote M2 macrophage polarization (44). In obese mice, inhibition of IL-4/IL-10 signaling diminishes iNKT cell- dependent glucose homeostasis (25). Also, short-term HFD feeding induces the expression of arginase 1, one of the M2 marker genes, in adipose tissue of WT mice, but not in CD1d KO and IL-4 KO mice, indicating that adipose iNKT cells rapidly respond to HFD and produce IL-4 to suppress inflammatory responses via induction of M2 macrophages (45). Moreover, it has been shown that IL-2 secreted by adipose iNKT cells is involved in immunosuppressive function of Treg cells through promoting IL-10 production of Treg cells in adipose tissue (29). Upon short term HFD feeding, the number of adipose Treg cells is elevated in WT mice, but not in CD1d ${ }^{\mathrm{AKO}}$ mice, underscoring the crucial roles of adipocyte CD1d in the regulation of the antiinflammatory responses (33). Furthermore, it has been very recently reported that IFN $\gamma$ produced by adipose iNKT cells in lean adipose tissue can serve to limit the expansion of ATMs by killing pro-inflammatory macrophages via NK cell stimulation (46).

These findings propose that activity control of iNKT cells by adipocytes and lipid antigens appears to be the key for adipose tissue immune balance (Figure 1A). In contrast, Satoh et al. has reported that adipose iNKT cells would exhibit proinflammatory characteristics by secreting IFN $-\gamma$ because CD1d ${ }^{\mathrm{AKO}}$ mice show adipose tissue inflammation and insulin resistance in obesity (43). Although there is no clear answer to explain opposite phenotypes in CD1d ${ }^{\mathrm{AKO}}$ mice above, it has been suggested that these differences are probably due to different types of control mice $\left(\mathrm{CD} 1 \mathrm{~d}^{\text {flox/+ }} v s \mathrm{CD} 1 \mathrm{~d}^{\text {flox/flox }}\right)$ and differences in high-fat diet (HFD) composition (tallow and safflower oil of high oleic type $v$ lard) (33). Moreover, it has been shown that adipose iNKT cells can be classified into several subpopulations that reveal either pro-inflammatory responses or antiinflammatory responses (46), implying that characteristics of adipose iNKT cells might be affected by multilateral relationships between lipid antigen species and iNKT cell subtypes. Thus, it seems that veiled traits of adipose iNKT cells could be further uncovered when lipid antigens loaded on adipocytes and subtypes of adipose iNKT cells are identified in future studies.

\section{Adipocyte Turnover Control by Lipid Antigen(s)}

Yearly, $10 \%$ of human adipocytes are dead and replaced with new adipocytes (47). Patients with cachexia, human immunodeficiency virus (HIV) or lipodystrophy syndrome show drastic loss of adipocytes (48-51). In obese mice, dead adipocytes are frequently found in epididymal adipose tissue (23, 52). Although adipocyte death is associated with adipose tissue inflammation in obesity, the causal factors that would induce adipocyte death have not been fully elucidated. Recently, it has been reported that, in hypertrophic adipocytes, the expression of Fas (CD95) is upregulated and is positively correlated with the degree of adipocyte death (Figure 1B) (23). Apoptotic pathway is induced in Fas-positive cells when Fas is bound to FasL (53). In obese adipose tissue, the portion of FasL-positive iNKT cells is significantly elevated, but not in CD4 and CD8 T cells, indicating that iNKT cells would be a major killer cell type to induce hypertrophic adipocyte death in obesity (23). Through in vitro 


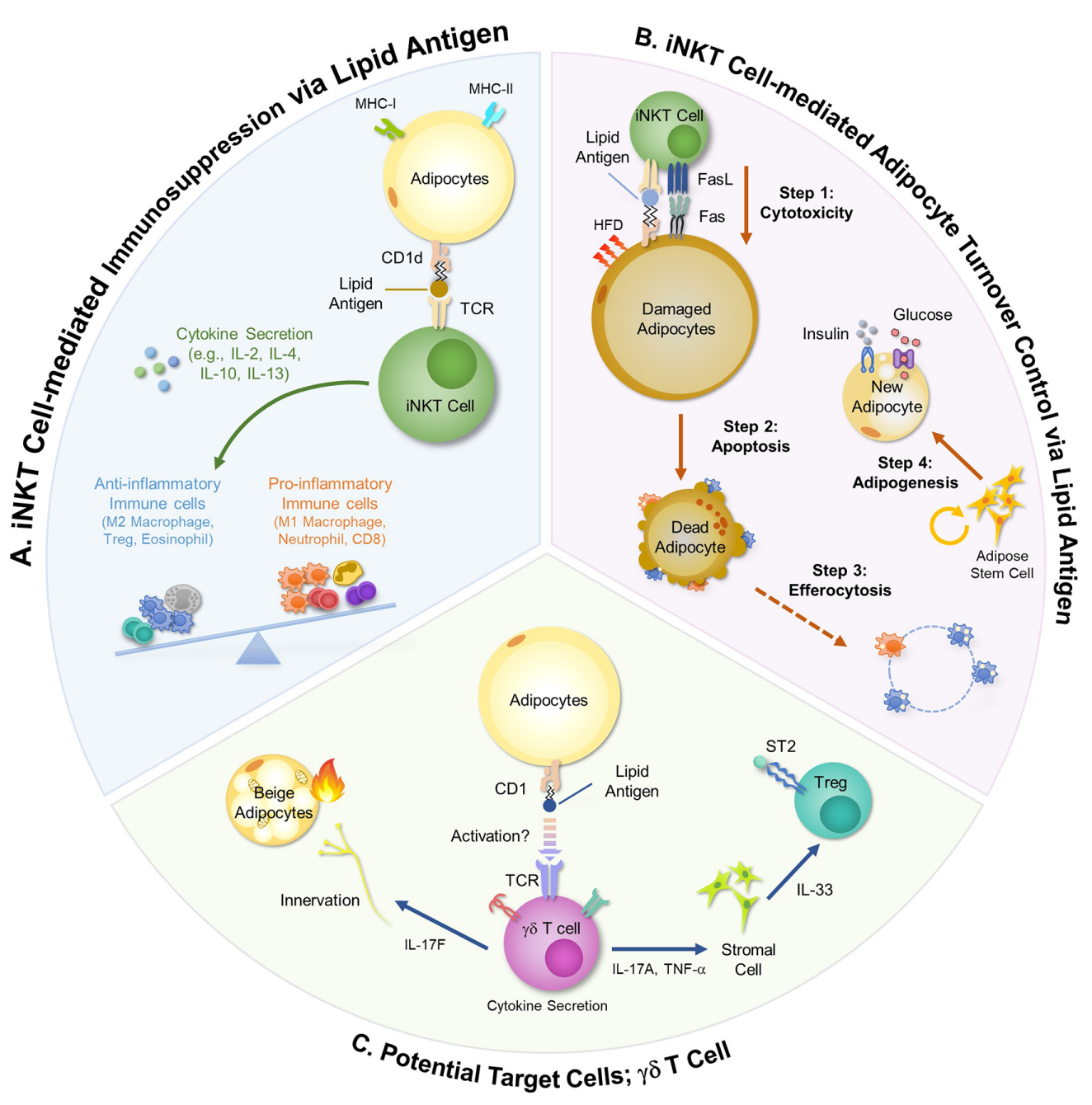

FIGURE 1 | Immunomodulatory Roles of Adipocytes using Lipid Antigens. Adipocytes modulate activities of adipose immune cells via lipid antigen presentation. iNKT cells and $\gamma \delta$ T cells are activated by lipid antigens and involve in the regulation of adipose tissue immunity and adipocyte functions. (A) In obesity, adipose iNKT cells activated by adipocyte-derived lipid antigens secret large amounts of anti-inflammatory cytokines such as IL-2, IL-4, IL-10, and IL-13. These cytokines stimulate Treg cells and polarize monocytes into anti-inflammatory M2 macrophages, thereby ameliorating pro-inflammatory responses in obese adipose tissue. (B) Adipose iNKT cells mediate hypertrophic and pro-inflammatory adipocyte death in obesity. Long-term HFD (over 8 weeks) upregulates CD95L (FasL) and CD95 (Fas) in adipose iNKT cells and damaged adipocytes, respectively. Interaction between CD95L and CD95 selectively stimulates damaged adipocyte death. After macrophage-mediated efferocytosis, adipose stem cells proliferate and de novo adipogenesis is promoted, leading to the generation of insulin-sensitive new adipocytes. (C) Given that $\gamma \delta$ T cells recognize CD1-loaded lipid antigens, it has been suggested that adipocytes might regulate $\gamma \delta$ T cell activity. $\gamma \delta$ T cells secrete several cytokines such as IL-17 and TNF- $\alpha$, controlling beige adipocyte formation and innervation. In addition, $\gamma \delta$ T cells activate stromal cells to secrete IL-33, resulting in Treg cell recruitment.

and in vivo experiments, it has been shown that hypertrophic adipocytes with pro-inflammatory characteristics stimulate iNKT cells by lipid antigen presentation via CD1d (23). Then, the activated iNKT cells selectively kill hypertrophic and proinflammatory adipocytes (23). iNKT cell-mediated hypertrophic adipocyte death is consistently observed in both diet-induced obese mice and genetically obese $d b / d b$ mice (23). After iNKT cell-mediated adipocyte death, adipocyte stem cells proliferate and differentiate into new and small adipocytes exhibiting elevated insulin sensitivity (Figure 1B) $(23,54)$. Together, it has been suggested that, in obesity, activity control of iNKT cells by adipocytes is crucial for adipocyte turnover, contributing to the improvement of insulin sensitivity.

\section{Adipocyte Death and Adipose Tissue Inflammation}

Although adipocyte death and ATMs surrounding dead adipocytes are frequently observed in obesity, the relationship between adipocyte death and inflammation remains elusive. Activation of iNKT cells by $\alpha$-GC administration into HFDfed obese mice induces apoptosis of hypertrophic adipocytes, accompanied by the increase in the portion of M2 macrophages 
compared to that of M1 macrophages (23). Similarly, the number of CD206 and CD301-positive M2-macrophages increases when adipocyte-specific apoptosis is induced in FAT-ATTACK mice (55). It seems that transient induction of apoptosis in adipocytes would upregulate anti-inflammatory responses. On the other hand, continuous adipocyte death resulted from chronic inflammation or deficiency of key enzymes involved in sphingolipid synthesis and mevalonate pathway often causes systemic pro-inflammatory responses $(56,57)$. Furthermore, if apoptotic cells are not rapidly and properly cleared by efferocytosis, the membrane of apoptotic cells is ruptured and transformed into necrosis-like cells, provoking inflammation. Thus, it is likely that controversial results of adipocyte death on adipose tissue inflammation would be due to several factors: whether types of adipocyte death are apoptotic or necrotic, whether adipocyte death is transient or persistent, and whether debris of dead adipocytes are well cleared.

The clearance of apoptotic cells by professional and nonprofessional phagocytes is essential for maintenance of tissue homeostasis (58). In response to apoptotic cells, macrophages suppress production of pro-inflammatory cytokines and enhance secretion of molecules that dampen inflammation, and mediate resolution and repair. Thus, defective efferocytosis leads to inflammation and impaired resolution, underlying various chronic inflammatory diseases such as atherosclerosis, obesity, diabetes, cardiovascular diseases, and cancer (58). In obese mice, macrophages appear to exhibit impaired efferocytosis, which is associated with higher number of apoptotic cells and greater expression of pro-inflammatory cytokines within wounds (59, $60)$. It has been proposed that defects of omega-3 fatty acids, erythropoietin, and MER proto-oncogene tyrosine kinase would suppress efferocytosis of dying/dead cells in atherosclerotic lesions, skin, and heart in obesity (58). However, to date, most studies have not focused on clearance of dead adipocytes, although dead adipocytes and ATMs surrounding them are abundantly observed in obesity. Future studies are required to unravel complex relationships between adipocyte death, efferocytosis, and adipose tissue inflammation.

\section{$\gamma \delta$ T Cells: Potential Target Cells of Adipocytes}

$\gamma \delta \mathrm{T}$ cell is one of the innate lymphocytes that are not restricted to $\mathrm{MHC}$ molecules but recognize CD1 molecules. In adipose tissue, $\gamma \delta$ T cells exhibit resident characteristics and occupy 5$15 \%$ of total T cells (26). Upon HFD, the number of $\gamma \delta \mathrm{T}$ cells increases and they promote accumulation of pro-inflammatory macrophages, worsening adipose tissue inflammation and insulin resistance (30). In contrast, it has been shown that IL$17 \mathrm{~A}$-producing $\gamma \delta \mathrm{T}$ cells are involved in the maintenance of adipose Treg population by promoting secretion of IL-33 from stromal cells, contributing to suppression of adipose tissue inflammation (Figure 1C) (26). In addition, under short term ketogenic diet (KD) which contains high fat and low carbohydrate, $\gamma \delta \mathrm{T}$ cells suppress adipose tissue inflammation and protect metabolic dysregulation through increasing expression of genes related to tissue repair (61). Conversely, long-term KD drastically decrease the number of $\gamma \delta \mathrm{T}$ cells and aggravates obesity and glucose intolerance (61). Although it remains to be clarified whether adipose $\gamma \delta \mathrm{T}$ cells would upregulate or downregulate inflammatory responses in adipose tissue, it seems that $\gamma \delta \mathrm{T}$ cell could play certain roles in inflammatory responses in adipose tissue. In addition to the regulation of adipose tissue inflammation, $\gamma \delta \mathrm{T}$ cells modulate adipocyte functions such as lipolysis and thermogenesis (26). In brown and subcutaneous adipose tissue, $\gamma \delta \mathrm{T}$ cells boost thermogenic programs by stimulating IL-33 secretion in stromal cells or promoting innervation in adipose tissue (Figure 1C) $(26,27)$. Given that $\gamma \delta$ T cells could recognize lipid antigens loaded on CD1 family, it is plausible to speculate that adipocytes would function as potential APCs in adipose tissue.

\section{RELATIONSHIP BETWEEN LIPID METABOLISM IN ADIPOCYTES AND ADIPOSE TISSUE IMMUNITY}

In adipose tissue, lipid metabolism is dynamically regulated upon diverse physiological conditions such as fasting, HFD, and aging. If lipid metabolism is dysregulated in adipocytes due to environmental or genetic factors, adipose tissue immunity and whole body energy metabolism are distorted. It has been suggested that endogenous lipids such as free fatty acids (FFAs) and eicosanoids modulate innate and adaptive immune cells (62). Furthermore, HFD provokes uncontrolled basal lipolysis and promotes unnecessary release of FFAs, causing imbalanced immune responses in adipose tissue. Also, when lipid storage capacity of adipocytes is defective by ablation of lipid droplet (LD) binding proteins such as Perilipin1 (Plin1), the levels of triglyceride and FFAs are elevated in adipose tissue and serum, which is accompanied by adipose tissue inflammation and insulin resistance (63). In this section, we cover how adipocytes regulate adipose immune responses by controlling lipid metabolism.

\section{Regulation of Adipose Immune Responses by Lipid Metabolites}

Lipid metabolites are associated with numerous human diseases, including atherosclerosis, rheumatoid arthritis, and other inflammation-linked metabolic diseases (64). While it has been considered for a long time that lipid metabolites are key energy sources, the importance of lipid metabolites as signaling molecules has been accumulated (65-67). Eicosanoids, certain FFAs, and FFA derivatives are able to act as signaling molecules in the regulation of immune responses (64). Among them, several lipid metabolites are produced by adipocytes or adipose tissues (19-21). Palmitoleate (C16:1n7), a long-chain monounsaturated FA, is produced through de novo lipogenesis in adipose tissue and downregulates pro-inflammatory gene expressions in macrophages (68-71). Also, in adipocytes, palmitic acid esters of hydroxy stearic acids (PAHSAs) 
synthesized by carbohydrate response element binding protein (ChREBP) regulate adipose tissue inflammation. While adipocyte-specific ChREBP knockout $\left(\mathrm{ChREBP}^{\mathrm{AKO}}\right)$ mice exhibit decreased PAHSA levels and increased ATMs in adipose tissue, PAHSA administration ameliorates pro-inflammatory responses in adipose tissue of ChREBP ${ }^{\mathrm{AKO}}$ mice (72).

In addition to de novo lipogenesis, certain lipid metabolites which regulate adipose tissue inflammation are produced by lipolysis. Recently, it has been shown that Plin1 inhibits futile prostaglandin secretion to restrict pro-inflammatory responses in adipose tissue (63). Plin1 deficiency in adipocytes impairs lipid storage into LDs and stimulates lipolysis, causing adipose tissue loss and unnecessary leakage of pro-inflammatory lipid metabolites. In adipose tissue of Plin 1 KO mice (Figure 2), pro-inflammatory gene expression and M1-type ATM accumulation are increased. Suppression of lipolysis by knockdown or inhibition of lipases attenuates the effects of Plin1-deficient adipocytes on monocyte migration. Moreover, lipidomic analysis and administration of cyclooxygenase inhibitor indicate that enhanced adipose tissue inflammation is mediated by excessive prostaglandin $\mathrm{E}_{2}\left(\mathrm{PGE}_{2}\right)$ secretion in Plin1-deficient adipocytes (62). Thus, it has been proposed that reducing futile lipolysis in adipocytes could downregulate adipose tissue inflammation through the control of proinflammatory lipid metabolite secretion (63).

Circulating FFAs are elevated in obesity and lipodystrophy, which is closely related to metabolic disorders including type 2 diabetes and atherosclerosis. FFAs including palmitic acids are able to activate inflammatory responses and also used to produce ceramides. Ceramides are one of important metabolites whose levels are elevated in obesity (73). Increased ceramides contributes to adipose tissue inflammation and dysregulation of energy homeostasis. In macrophages, ceramide initiates p38 MAPK and JNK signaling pathways, polarizing ATMs towards M1 macrophages (74). Moreover, ceramides activate NLR family pyrin domain containing 3 (NLRP3) inflammasome and promote secretion of IL-1 $\beta$ and IL-18 in macrophages, aggravating adipose tissue inflammation and glucose intolerance in obesity (75).

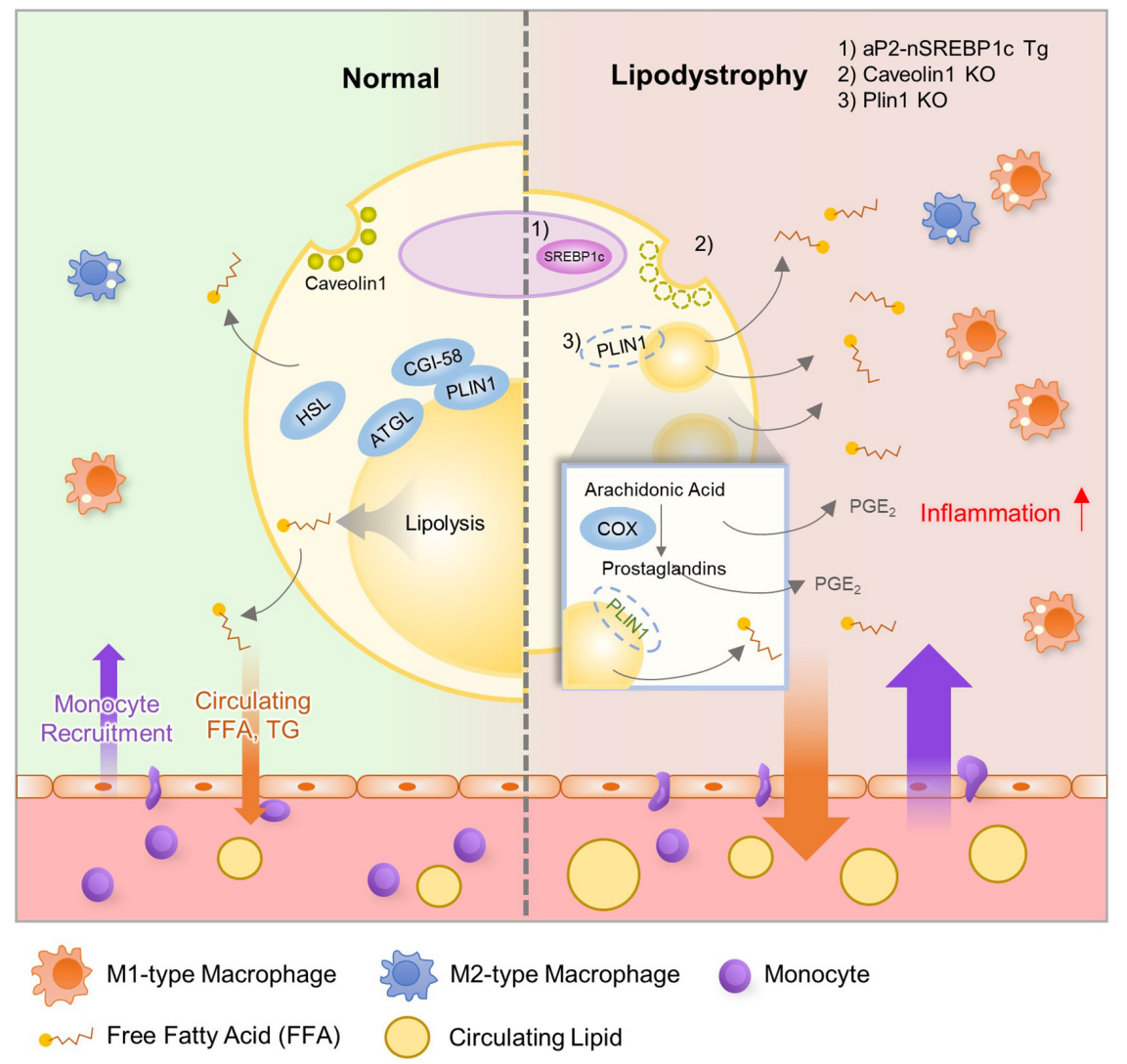

FIGURE 2 | Relationship between Lipodystrophy and Adipose Tissue Inflammation. In adipocytes, lipid metabolism is well balanced by several genes, including Srebp1c, Atgl, Hsl, Cgi-58, Plin1, and Fsp27. However, lean subjects with lipodystrophy show dysregulated lipid metabolism with increased inflammation and insulin resistance. Evidence suggests that dysregulation of lipid metabolism could influence adipose tissue inflammation in lipodystrophy. aP2-nuclear form of SREBP1c transgenic (aP2-nSREBP1c Tg) mice and Caveolin1 KO mice show significantly reduced fat mass and display metabolic dysregulation including insulin resistance and dyslipidemia. In addition, Plin1 deficiency induces partial fat loss, leakage of FFAs, ATM accumulation, dyslipidemia and systemic insulin resistance. In these lipodystrophic models, several lipid metabolites such as FFA and PGE2 recruit monocytes into adipose tissue and worsen adipose tissue inflammation. 


\section{Lipodystrophy and Adipose Tissue Inflammation}

Although lipodystrophy and adipose tissue expansion such as obesity are somewhat opposite in terms of adipose tissue mass, both pathological states often exhibit similar metabolic dysregulation (76-78). Obesity-induced low-grade and chronic inflammation is one of the major factors to promote insulin resistance $(12,79)$. Also, severely lean patients with lipodystrophy or cachexia reveal enhanced inflammation with insulin resistance even though underlying mechanisms are not fully uncovered. Nonetheless, it has been suggested that immune responses in adipose tissue could be involved in the development of insulin resistance in lipodystrophy $(80,81)$. Proinflammatory gene expression and ATM accumulation are promoted in adipose tissue of lipodystrophic animal models even with less adipose tissue mass. For instance, aP2-nuclear form of sterol regulatory element-binding protein 1c (SREBP1c) transgenic (aP2-nSREBP1c Tg) mice and Caveolin1 KO mice show significantly reduced fat mass and display metabolic dysregulation including insulin resistance and dyslipidemia $(82-84)$. In these lipodystrophic models, increases in proinflammatory cytokine and ATM accumulation are observed in adipose tissue (Figure 2) (84). In addition, Plin1 deficiency reveals partial fat loss, ATM accumulation, dyslipidemia and systemic insulin resistance in both mouse and human $(63,85)$. In aP2-nSREBP1c Tg mice, anti-inflammatory strategies such as salicylate treatment or crossing with myeloid cell-specific I $K B$ kinase (IKK $\beta)$ KO mice do not ameliorate insulin resistance (83). On the other hand, in Plin1 KO mice, macrophage depletion by clodronate treatment or inhibition of synthesis of proinflammatory lipid metabolites in adipocytes mitigates systemic insulin resistance (63). These results indicate that the precise relationship between adipose tissue inflammation and systemic energy homeostasis remains to be thoroughly elucidated under lipodystrophic conditions.

\section{Aging-Related Decrease in Lipolysis}

Aging is a chronic and complex physiological process that gradually deteriorates energy homeostasis (86). Dysfunction of adipose tissue is one of the major factors to provoke agingrelated metabolic disorders including type 2 diabetes and cardiovascular diseases. In the elderly, the processes of lipolysis and lipid storage in adipose tissue are not properly controlled. As a result, mobilization of FFAs is dysregulated, causing visceral adiposity, lower exercise capacity, and cold intolerance. These alterations of adipose tissue are closely associated with adipose tissue immunity (87). Adipose macrophages and B cells are involved in age-related reduction of lipolytic activity. In aged mouse model, macrophages degrade catecholamine in a NLRP3 inflammasome-dependent manner in adipose tissue, driving lipolysis resistance in adipocytes (88). When NLRP3 inflammasome is activated in aged macrophages, the expression of monoamine oxidase (MAOA) which is known to degrade noradrenaline is increased by growth differentiation factor-3 (88). Moreover, aging stimulates expansion of adipose B cells in fat-associated lymphoid clusters (FALC), which is mediated by activation of NLRP3 inflammasome and IL-1 signaling (89). It has been shown that inhibition of MAOA in macrophages or depletion of $B$ cell reverses the age-related decline in lipolysis and restore age-associated adipose tissue impairment (89). However, in human adipose tissue, the major cell type expressing MAOA is different from mice. In human adipose tissue, MAOA is mainly expressed in mature adipocytes, unlike mice, contributing to aging-associated reduction in lipolysis (90).

\section{THE NOVEL ROLES OF ADIPOSE STEM CELLS IN THE REGULATION OF ADIPOSE TISSUE IMMUNITY}

ASCs are composed of heterogeneous populations and each population has unique characteristics. ASCs are largely divided into adipogenic and non-adipogenic subtypes (91). Adipogenic ASCs preferentially differentiate into adipocytes in response to excess energy, which increases energy storage capacity of adipose tissue. This process, called hyperplasia, mediates healthy adipose tissue expansion and attenuates adipose tissue inflammation in obesity. On the other hand, non-adipogenic ASCs secrete various pro- and anti-inflammatory cytokines, lipokines, and collagens, which could affect activity and recruitment of adipose immune cells. In addition, it appears that non-adipogenic ASCs would be key players for distinct immune responses between subcutaneous white adipose tissue (sWAT) and visceral white adipose tissue (vWAT). As the roles of adipogenic ASCs have been well discussed in previous reviews $(92,93)$, we cover the novel roles of non-adipogenic ASCs in the regulation of adipose tissue immunity.

\section{Novel Roles of ASCs in the Regulation of Adipose Tissue Immunity}

Adipose tissue is divided into adipocyte and stromal vascular cell (SVC) fraction, and SVC fraction is further classified into ASCs $\left(\mathrm{CD} 45^{-} \mathrm{CD} 31^{-}\right)$, immune cell $\left(\mathrm{CD}^{+} 5^{+}\right)$, endothelial cell $\left(\mathrm{CD} 31^{+}\right)$, and red blood cell. In the last several years, single cell RNAsequencing (scRNA-seq) has been used to reveal subpopulation and characteristics of ASCs, providing compelling evidence that ASCs would exhibit molecular heterogeneity and functional diversity $(94,95)$. Interestingly, it has been proposed that ASCs not only have adipogenic potential, but also exhibit antiadipogenic and immunomodulatory roles (96).

ASCs secrete pro-inflammatory cytokines (e.g., IL-6, IL-8, IL11 , TNF- $\alpha$ ), anti-inflammatory cytokines (e.g., TGF- $\beta$, IL-10), growth factors, chemokines (Cxcl5), and lipokines (PGE2) (97). Upon HFD, the number of fibro-inflammatory stem cells ( $\operatorname{lin}^{-} \mathrm{Pdgfr} \beta^{+} \mathrm{Ly} 6 \mathrm{c}^{+}$cells, $\operatorname{lin}^{-} \mathrm{Pdgfr} \alpha^{+} \mathrm{Gp} 38^{+} \mathrm{CD} 9^{+}$) is upregulated and they highly express pro-inflammatory cytokines (e.g., IL-6, Ccl2, Cxcl2, Cxcl10) and extracellular matrix components (e.g., Colla1, Col3a1), causing adipose tissue inflammation (Figure 3) (98-100). In human and mouse, CXCL1 ${ }^{+}$mesothelial cells (CD45 $\mathrm{CD} 31^{-}$Ter $119^{-} \mathrm{CD}^{-} 1^{-} \mathrm{PDPN}^{+/}$) recruit neutrophils into the 


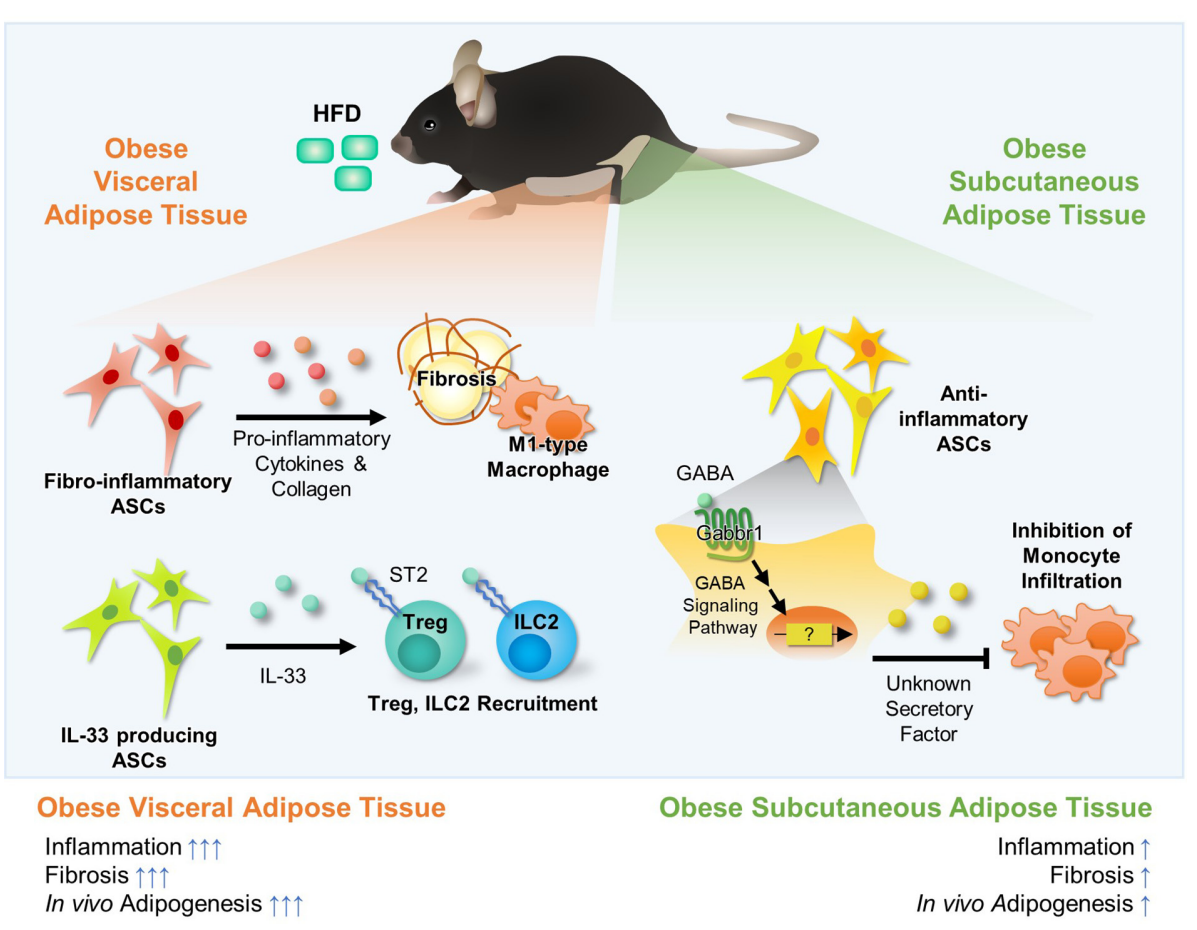

FIGURE 3 | Fat Depot-specific Roles of Adipocyte Stem Cells (ASCs) in the Regulation of Adipose Tissue Immunity. White adipose tissues consist of major two fat depots; visceral adipose tissue and subcutaneous adipose tissue. These two fat depots exhibit several differences in inflammatory responses, fibrosis, and adipogenesis. ASCs are major cell types comprising of adipose tissue, and they are largely divided into adipogenic and non-adipogenic clusters. In visceral adipose tissue, there are fibro-inflammatory ASCs (lin-Pdgfr $\beta+$ Ly6c+ cells or lin-Pdgfr $\alpha+G p 38+C D 9+)$. The number of fibro-inflammatory ASCs increases in obesity and they secret pro-inflammatory cytokines (e.g., IL-6, Ccl2) and ECM components (e.g., Col1a1, Col3a1), promoting fibrosis. Moreover, it has been reported that IL-33 producing non-adipogenic ASCs (in-Pdgfr $\alpha+$ PPAR $\gamma$-) are involved in recruitment of Treg and ILC2 via IL-33 secretion, which suppresses inflammation in visceral adipose tissue. Recently, it was reported that, in subcutaneous adipose tissue, ASCs (CD31-CD34+Sca1+) suppress monocyte infiltration, which is potentially regulated by GABA signaling. However, the secretory factors that inhibit monocyte infiltration in subcutaneous adipose tissue have not been elucidated yet.

FALC via protein arginine deiminase 4 during peritonitis and promote the aggregation of neutrophils, providing first layer of immunological defense in vWAT (101). On the other hand, another population of ASCs that suppress adipose tissue inflammation has been also reported (102-104). Lin $\mathrm{Pdgfr}^{+} \mathrm{Scal}^{+}$population is a major source of IL-33 in vWAT (Figure 3) (102). IL-33 ${ }^{+}$ASCs recruit anti-inflammatory Treg and ILC2 cells in lean subjects, contributing to suppression of adipose tissue inflammation (102).

It has been shown that ASCs would be the key cell type that explains distinct inflammatory patterns between sWAT and vWAT in obesity (Figure 3) (100, 103, 104). In obese mice, vWAT shows the higher number of infiltrated macrophages and crown-like structures, whereas sWAT is less prone to inflammation. However, it is still unknown which factors make the differences in inflammatory responses between the two major fat depots in obesity. Very recently, it has been demonstrated that SVCs of sWAT secrete certain factors to repress monocyte recruitment, and that transplantation of ASCs derived from sWAT into vWAT suppresses ATM infiltration in vWAT (103, 104). Interestingly, gamma-aminobutyric acid (GABA) signaling is one of the most differentially expressed pathways between
sWAT and vWAT in obesity. In HFD-induced obese mice, GABA treatment inhibits ATM infiltration in sWAT-selective manner, but not in vWAT (102). Thus, it has been proposed that GABA signaling in ASCs might be one of the potential pathways that could selectively suppresses inflammatory responses in sWAT (103).

Given that ASCs have high proliferation rate, adipogenic potential, and immunomodulatory roles, they have been considered therapeutic target for recovery of adipose tissue homeostasis. Recently developed scRNA-seq analysis dissects ASCs into three or more subpopulations with their own distinct functions. Proliferative and stem cell-like ASCs can be used in tissue repair and regenerative processes. Adipogenic and anti-adipogenic subpopulations of ASC can increase or decrease buffering capacity of adipose tissue, respectively. In addition, ASCs that exhibit immunomodulatory properties can be used to control inflammatory responses of adipose tissues. Although complicated networks between ASCs and adipose tissue constituent cells need to be further investigated, recent approaches equipped with high techs would provide new therapeutic targets against adipose tissue dysfunction, particularly, in obesity. 


\section{LIMITATIONS AND FUTURE DIRECTIONS}

There are several points to be solved in future studies. First, it remains elusive which kinds of endogenous lipid antigens would be presented by adipocyte CD1d in obesity. Even though $\alpha$-GC has been used as an activator for iNKT cells, $\alpha$-GC is an exogenous and quite potent activator, which might be different from patho-physiologic conditions. Second, it is required to identify antigen presenting cells and lipid antigens that regulate the activity of $\gamma \delta \mathrm{T}$ cells in adipose tissue. Third, the mechanisms of ATM recruitment by lipid metabolites such as $\mathrm{PGE}_{2}$ should be elucidated in future studies. Lastly, while recent technical advances (e.g., scRNA-seq) have proposed novel subpopulations of adipocytes and discovered new relationships between adipocyte subpopulations and immune cells, it remains to be validated with proper in vivo models (105-108). Also, there are still huge technical obstacles in the analysis of lipid profiles from each adipocyte subpopulations as well as immune cells.

\section{CONCLUSION}

Lipids are key energy sources and primary building blocks for plasma membranes and intracellular organelles. Moreover, lipid metabolites participate in numerous signal transduction and regulate multiple cellular functions. Recently, it has been suggested that lipid metabolites are crucial bioactive molecules in immune system (18-20). Here, we have discussed the immunomodulatory roles of lipid metabolites of adipocytes upon metabolic stimuli. In response to altered metabolic environments, adipocytes sensitively and dynamically control lipid metabolism and present or secrete lipid metabolites to

\section{REFERENCES}

1. Choe SS, Huh JY, Hwang IJ, Kim JI, Kim JB. Adipose Tissue Remodeling: Its Role in Energy Metabolism and Metabolic Disorders. Front Endocrinol (Lausanne) (2016) 7:30. doi: 10.3389/fendo.2016.00030

2. Huh JY, Park YJ, Ham M, Kim JB. Crosstalk between adipocytes and immune cells in adipose tissue inflammation and metabolic dysregulation in obesity. Mol Cells (2014) 37:365-71. doi: 10.14348/molcells.2014.0074

3. Haluzik M, Haluzikova D. Endocrine function of adipose tissue and its clinical use: still waiting for the prime time? Expert Rev Endocrinol Metab (2011) 6:5-8. doi: 10.1586/eem.10.69

4. Zmora N, Bashiardes S, Levy M, Elinav E. The Role of the Immune System in Metabolic Health and Disease. Cell Metab (2017) 25:506-21. doi: 10.1016/ j.cmet.2017.02.006

5. Brestoff JR, Artis D. Immune regulation of metabolic homeostasis in health and disease. Cell (2015) 161:146-60. doi: 10.1016/j.cell.2015.02.022

6. Ganeshan K, Chawla A. Metabolic regulation of immune responses. Annu Rev Immunol (2014) 32:609-34. doi: 10.1146/annurev-immunol-032713120236

7. Choe SS, Kim JB. Hypoxia-inducible factors: new strategies for treatment of obesity-induced metabolic diseases. Postgrad Med J (2020) 96:451-2. doi: 10.1136/postgradmedj-2019-136428

8. Lee YS, Li P, Huh JY, Hwang IJ, Lu M, Kim JI, et al. Inflammation is necessary for long-term but not short-term high-fat diet-induced insulin resistance. Diabetes (2011) 60:2474-83. doi: 10.2337/db11-0194 modulate characteristics of adipose immune cells. Thus, it is plausible to speculate that adipocytes not only use lipid metabolites to maintain their structures and functions, but also actively utilize lipid metabolites as key messengers to communicate with adipose immune cells. The interplay between adipocytes and adipose immune cells leads to finetuning adipose tissue immunity and adipose tissue remodeling, which eventually contributes to maintenance of systemic energy metabolism. Nonetheless, there are remaining issues to be solved in future studies. For instance, the lipid antigen presented by adipocytes and lipid metabolites secreted by adipocytes are not fully identified. There have been technical difficulties such as extraction of lipids, identification of specific lipid species, and quantitation of the vast array of lipids. Thus, solving these issues will enhance our insights about the mechanisms by which adipocytes govern adipose tissue immunity, and further suggest new therapeutic approaches on metabolic complications caused by adipose tissue inflammation.

\section{AUTHOR CONTRIBUTIONS}

JP, JHS, SMH, YJP, JYH, SSC, and JBK contributed to the writing of the manuscript under JK's supervision. All authors contributed to the article and approved the submitted version.

\section{FUNDING}

This work was supported by the National Research Foundation of Korea (NRF) grant funded by the Korea government (MSIT) (No. NRF-2020R1A3B2078617).
9. Ham M, Choe SS, Shin KC, Choi G, Kim J-W, Noh J-R, et al. Glucose-6phosphate dehydrogenase deficiency improves insulin resistance with reduced adipose tissue inflammation in obesity. Diabetes (2016) 65 (9):2624-38. doi: 10.2337/db16-0060

10. Choe SS, Shin KC, Ka S, Lee YK, Chun JS, Kim JB. Macrophage HIF-2alpha Ameliorates Adipose Tissue Inflammation and Insulin Resistance in Obesity. Diabetes (2014) 63:3359-71. doi: 10.2337/db13-1965

11. Chawla A, Nguyen KD, Goh YP. Macrophage-mediated inflammation in metabolic disease. Nat Rev Immunol (2011) 11:738-49. doi: 10.1038/nri3071

12. Olefsky JM, Glass CK. Macrophages, inflammation, and insulin resistance. Annu Rev Physiol (2010) 72:219-46. doi: 10.1146/annurev-physiol-021909135846

13. Weisberg SP, McCann D, Desai M, Rosenbaum M, Leibel RL, Ferrante AW Jr. Obesity is associated with macrophage accumulation in adipose tissue. J Clin Invest (2003) 112:1796-808. doi: 10.1172/JCI200319246

14. Xu H, Barnes GT, Yang Q, Tan G, Yang D, Chou CJ, et al. Chronic inflammation in fat plays a crucial role in the development of obesity-related insulin resistance. J Clin Invest (2003) 112:1821-30. doi: 10.1172/ JCI200319451

15. Castoldi A, Naffah de Souza C, Câmara NOS, Moraes-Vieira PM. The Macrophage Switch in Obesity Development. Front Immunol (2016) 6:6377. doi: 10.3389/fimmu.2015.00637

16. McLaughlin T, Ackerman SE, Shen L, Engleman E. Role of innate and adaptive immunity in obesity-associated metabolic disease. J Clin Invest (2017) 127:5-13. doi: 10.1172/JCI88876 
17. Wang H, Shen L, Sun X, Liu F, Feng W, Jiang C, et al. Adipose group 1 innate lymphoid cells promote adipose tissue fibrosis and diabetes in obesity. Nat Commun (2019) 10:3254. doi: 10.1038/s41467-019-11270-1

18. Park YJ, Park J, Huh JY, Hwang I, Choe SS, Kim JB. Regulatory Roles of Invariant Natural Killer T Cells in Adipose Tissue Inflammation: Defenders Against Obesity-Induced Metabolic Complications. Front Immunol (2018) 9:1311. doi: 10.3389/fimmu.2018.01311

19. Mazid MA, Chowdhury AA, Nagao K, Nishimura K, Jisaka M, Nagaya T, et al. Endogenous 15-deoxy-Delta(12,14)-prostaglandin J(2) synthesized by adipocytes during maturation phase contributes to upregulation of fat storage. FEBS Lett (2006) 580:6885-90. doi: 10.1016/j.febslet.2006.11.049

20. Gartung A, Zhao J, Chen S, Mottillo E, VanHecke GC, Ahn YH, et al. Characterization of Eicosanoids Produced by Adipocyte Lipolysis: IMPLICATION OF CYCLOOXYGENASE-2 IN ADIPOSE INFLAMMATION. J Biol Chem (2016) 291:16001-10. doi: 10.1074/jbc. M116.725937

21. Hu X, Cifarelli V, Sun S, Kuda O, Abumrad NA, Su X. Major role of adipocyte prostaglandin E2 in lipolysis-induced macrophage recruitment. J Lipid Res (2016) 57:663-73. doi: 10.1194/jlr.M066530

22. Uysal KT, Wiesbrock SM, Marino MW, Hotamisligil GS. Protection from obesity-induced insulin resistance in mice lacking TNF-alpha function. Nature (1997) 389:610-4. doi: 10.1038/39335

23. Park J, Huh JY, Oh J, Kim JI, Han SM, Shin KC, et al. Activation of invariant natural killer $\mathrm{T}$ cells stimulates adipose tissue remodeling via adipocyte death and birth in obesity. Genes Dev (2019) 33(23-24):1657-72. doi: 10.1101/ gad.329557.119

24. Huh JY, Kim JI, Park YJ, Hwang IJ, Lee YS, Sohn JH, et al. A novel function of adipocytes in lipid antigen presentation to iNKT cells. Mol Cell Biol (2013) 33:328-39. doi: 10.1128/MCB.00552-12

25. Lynch L, Nowak M, Varghese B, Clark J, Hogan AE, Toxavidis V, et al. Adipose tissue invariant NKT cells protect against diet-induced obesity and metabolic disorder through regulatory cytokine production. Immunity (2012) 37:574-87. doi: 10.1016/j.immuni.2012.06.016

26. Kohlgruber AC, Gal-Oz ST, LaMarche NM, Shimazaki M, Duquette D, Koay $\mathrm{HF}$, et al. $\gamma \delta \mathrm{T}$ cells producing interleukin-17A regulate adipose regulatory $\mathrm{T}$ cell homeostasis and thermogenesis. Nat Immunol (2018) 19:464-74. doi: 10.1038/s41590-018-0094-2

27. Hu B, Jin C, Zeng X, Resch JM, Jedrychowski MP, Yang Z, et al. $\gamma \delta$ T cells and adipocyte IL-17RC control fat innervation and thermogenesis. Nature (2020) 578:610-4. doi: 10.1038/s41586-020-2028-z

28. van Eijkeren RJ, Krabbe O, Boes M, Schipper HS, Kalkhoven E. Endogenous lipid antigens for invariant natural killer $\mathrm{T}$ cells hold the reins in adipose tissue homeostasis. Immunology (2018) 153:179-89. doi: 10.1111/imm. 12839

29. Lynch L, Michelet X, Zhang S, Brennan PJ, Moseman A, Lester C, et al. Regulatory iNKT cells lack expression of the transcription factor PLZF and control the homeostasis of $\mathrm{T}(\mathrm{reg})$ cells and macrophages in adipose tissue. Nat Immunol (2015) 16:85-95. doi: 10.1038/ni.3047

30. Johnson MD, Witherden DA, Havran WL. The Role of Tissue-resident T Cells in Stress Surveillance and Tissue Maintenance. Cells (2020) 9(3):686. doi: 10.3390/cells9030686

31. Luoma AM, Castro CD, Mayassi T, Bembinster LA, Bai L, Picard D, et al. Crystal Structure of V $\delta 1 \mathrm{~T}$ Cell Receptor in Complex with CD1d-Sulfatide Shows MHC-like Recognition of a Self-Lipid by Human $\gamma \delta \mathrm{T}$ Cells. Immunity (2013) 39:1032-42. doi: 10.1016/j.immuni.2013.11.001

32. Luoma AM, Castro CD, Adams EJ. $\gamma \delta \mathrm{T}$ cell surveillance via CD1 molecules. Trends Immunol (2014) 35:613-21. doi: 10.1016/j.it.2014.09.003

33. Huh JY, Park YJ, Kim JB. Adipocyte CD1d determines adipose inflammation and insulin resistance in obesity. Adipocyte (2018) 7:129-36. doi: 10.1080/ 21623945.2018.1440928

34. Huh JY, Park J, Kim JI, Park YJ, Lee YK, Kim JB. Deletion of CD1d in adipocytes aggravates adipose tissue inflammation and insulin resistance in obesity. Diabetes (2017) 66:835-47. doi: 10.2337/db16-1122

35. Barral DC, Brenner MB. CD1 antigen presentation: how it works. Nat Rev Immunol (2007) 7:929-41. doi: 10.1038/nri2191

36. Somnay-Wadgaonkar K, Nusrat A, Kim HS, Canchis WP, Balk SP, Colgan SP, et al. Immunolocalization of CD1d in human intestinal epithelial cells and identification of a beta2-microglobulin-associated form. Int Immunol (1999) 11:383-92. doi: 10.1093/intimm/11.3.383

37. Hannun YA, Obeid LM. Principles of bioactive lipid signalling: lessons from sphingolipids. Nat Rev Mol Cell Biol (2008) 9:139-50. doi: 10.1038/nrm2329

38. Rakhshandehroo M, van Eijkeren RJ, Gabriel TL, de Haar C, Gijzel SMW, Hamers N, et al. Adipocytes harbor a glucosylceramide biosynthesis pathway involved in iNKT cell activation. Biochim Biophys Acta Mol Cell Biol Lipids (2019) 1864:1157-67. doi: 10.1016/j.bbalip.2019.04.016

39. van Eijkeren RJ, Morris I, Borgman A, Markovska A, Kalkhoven E. Cytokine Output of Adipocyte-iNKT Cell Interplay Is Skewed by a Lipid-Rich Microenvironment. Front Endocrinol (2020) 11:479. doi: 10.3389/ fendo.2020.00479

40. van den Elzen P, Garg S, Leon L, Brigl M, Leadbetter EA, Gumperz JE, et al. Apolipoprotein-mediated pathways of lipid antigen presentation. Nature (2005) 437:906-10. doi: 10.1038/nature04001

41. Freigang S, Zadorozhny V, McKinney MK, Krebs P, Herro R, Pawlak J, et al. Fatty acid amide hydrolase shapes NKT cell responses by influencing the serum transport of lipid antigen in mice. J Clin Invest (2010) 120:1873-84. doi: 10.1172/JCI40451

42. Ververs FA, Kalkhoven E, Van't Land B, Boes M, Schipper HS. Immunometabolic Activation of Invariant Natural Killer T Cells. Front Immunol (2018) 9:1192. doi: 10.3389/fimmu.2018.01192

43. Satoh M, Hoshino M, Fujita K, Iizuka M, Fujii S, Clingan CS, et al. Adipocyte-specific CD1d-deficiency mitigates diet-induced obesity and insulin resistance in mice. Sci Rep (2016) 6:28473. doi: 10.1038/srep28473

44. Mantovani A, Sica A, Sozzani S, Allavena P, Vecchi A, Locati M. The chemokine system in diverse forms of macrophage activation and polarization. Trends Immunol (2004) 25:677-86. doi: 10.1016/j.it.2004. 09.015

45. Ji Y, Sun S, Xia S, Yang L, Li X, Qi L. Short term high fat diet challenge promotes alternative macrophage polarization in adipose tissue via natural killer T cells and interleukin-4. J Biol Chem (2012) 287:24378-86. doi: 10.1074/jbc.M112.371807

46. LaMarche NM, Kane H, Kohlgruber AC, Dong H, Lynch L, Brenner MB. Distinct iNKT Cell Populations Use IFN $\gamma$ or ER Stress-Induced IL-10 to Control Adipose Tissue Homeostasis. Cell Metab (2020) 32(2):243-58.e6. doi: 10.1016/j.cmet.2020.05.017

47. Spalding KL, Arner E, Westermark PO, Bernard S, Buchholz BA, Bergmann O, et al. Dynamics of fat cell turnover in humans. Nature (2008) 453:783-7. doi: 10.1038 /nature 06902

48. Prins JB, Walker NI, Winterford CM, Cameron DP. Human adipocyte apoptosis occurs in malignancy. Biochem Biophys Res Commun (1994) 205:625-30. doi: 10.1006/bbrc.1994.2711

49. Domingo P, Matias-Guiu X, Pujol RM, Francia E, Lagarda E, Sambeat MA, et al. Subcutaneous adipocyte apoptosis in HIV-1 protease inhibitorassociated lipodystrophy. AIDS (London England) (1999) 13:2261-7. doi: 10.1097/00002030-199911120-00008

50. Fischer-Posovszky P, Hebestreit H, Hofmann AK, Strauss G, Moller P, Debatin KM, et al. Role of CD95-mediated adipocyte loss in autoimmune lipodystrophy. J Clin Endocrinol Metab (2006) 91:1129-35. doi: 10.1210/ jc.2005-0737

51. Hussain I, Garg A. Lipodystrophy Syndromes. Endocrinol Metab Clinics North Am (2016) 45:783-97. doi: 10.1016/j.ecl.2016.06.012

52. Strissel KJ, Stancheva Z, Miyoshi H, Perfield, 2nd JW, DeFuria J, Jick Z, et al. Adipocyte death, adipose tissue remodeling, and obesity complications. Diabetes (2007) 56:2910-8. doi: 10.2337/db07-0767

53. Green DR, Ferguson TA. The role of Fas ligand in immune privilege. Nat Rev Mol Cell Biol (2001) 2:917-24. doi: 10.1038/35103104

54. Kim JI, Huh JY, Sohn JH, Choe SS, Lee YS, Lim CY, et al. Lipid-overloaded enlarged adipocytes provoke insulin resistance independent of inflammation. Mol Cell Biol (2015) 35:1686-99. doi: 10.1128/MCB.01321-14

55. Fischer-Posovszky P, Wang QA, Asterholm IW, Rutkowski JM, Scherer PE. Targeted deletion of adipocytes by apoptosis leads to adipose tissue recruitment of alternatively activated M2 macrophages. Endocrinology (2011) 152:3074-81. doi: 10.1210/en.2011-1031

56. Alexaki A, Clarke BA, Gavrilova O, Ma Y, Zhu H, Ma X, et al. De Novo Sphingolipid Biosynthesis Is Required for Adipocyte Survival and Metabolic 
Homeostasis. J Biol Chem (2017) 292:3929-39. doi: 10.1074/jbc.M116. 756460

57. Yeh YS, Jheng HF, Iwase M, Kim M, Mohri S, Kwon J, et al. The Mevalonate Pathway Is Indispensable for Adipocyte Survival. iScience (2018) 9:175-91. doi: 10.1016/j.isci.2018.10.019

58. Doran AC, Yurdagul A Jr., Tabas I. Efferocytosis in health and disease. Nat Rev Immunol (2019) 20(4):2547-67. doi: 10.1038/s41577-019-0240-6

59. Luo B, Wang Z, Zhang Z, Shen Z, Zhang Z. The deficiency of macrophage erythropoietin signaling contributes to delayed acute inflammation resolution in diet-induced obese mice. Biochim Biophys Acta Mol Basis Dis (2019) 1865:339-49. doi: 10.1016/j.bbadis.2018.10.005

60. Li S, Sun Y, Liang CP, Thorp EB, Han S, Jehle AW, et al. Defective phagocytosis of apoptotic cells by macrophages in atherosclerotic lesions of ob/ob mice and reversal by a fish oil diet. Circ Res (2009) 105:1072-82. doi: 10.1161/CIRCRESAHA.109.199570

61. Goldberg EL, Shchukina I, Asher JL, Sidorov S, Artyomov MN, Dixit VD. Ketogenesis activates metabolically protective gammadelta $\mathrm{T}$ cells in visceral adipose tissue. Nat Metab (2020) 2:50-61. doi: 10.1038/s42255-019-0160-6

62. Tessaro FH, Ayala TS, Martins JO. Lipid mediators are critical in resolving inflammation: a review of the emerging roles of eicosanoids in diabetes mellitus. BioMed Res Int (2015) 2015:568408. doi: 10.1155/2015/568408

63. Sohn JH, Lee YK, Han JS, Jeon YG, Kim JI, Choe SS, et al. Perilipin 1 (Plin1) deficiency promotes inflammatory responses in lean adipose tissue through lipid dysregulation. J Biol Chem (2018) 293:13974-88. doi: 10.1074/ jbc.RA118.003541

64. Shimizu T. Lipid mediators in health and disease: enzymes and receptors as therapeutic targets for the regulation of immunity and inflammation. Annu Rev Pharmacol Toxicol (2009) 49:123-50. doi: 10.1146/annurev.pharmtox. 011008.145616

65. Shimizu T, Wolfe LS. Arachidonic acid cascade and signal transduction. J neurochemistry (1990) 55:1-15. doi: 10.1111/j.1471-4159.1990.tb08813.x

66. Funk CD. Prostaglandins and leukotrienes: advances in eicosanoid biology. Science (New York NY) (2001) 294:1871-5. doi: 10.1126/science.294. 5548.1871

67. Masoodi M, Kuda O, Rossmeisl M, Flachs P, Kopecky J. Lipid signaling in adipose tissue: Connecting inflammation \& metabolism. Biochim Biophys Acta (BBA) - Mol Cell Biol Lipids (2015) 1851:503-18. doi: 10.1016/ j.bbalip.2014.09.023

68. Cao H, Gerhold K, Mayers JR, Wiest MM, Watkins SM, Hotamisligil GS. Identification of a lipokine, a lipid hormone linking adipose tissue to systemic metabolism. Cell (2008) 134:933-44. doi: 10.1016/j.cell.2008.07.048

69. Talbot NA, Wheeler-Jones CP, Cleasby ME. Palmitoleic acid prevents palmitic acid-induced macrophage activation and consequent p38 MAPKmediated skeletal muscle insulin resistance. Mol Cell Endocrinol (2014) 393:129-42. doi: 10.1016/j.mce.2014.06.010

70. Cimen I, Yildirim Z, Dogan AE, Yildirim AD, Tufanli O, Onat UI, et al. Double bond configuration of palmitoleate is critical for atheroprotection. Mol Metab (2019) 28:58-72. doi: 10.1016/j.molmet.2019.08.004

71. Chan KL, Pillon NJ, Sivaloganathan DM, Costford SR, Liu Z, Théret M, et al. Palmitoleate Reverses High Fat-induced Proinflammatory Macrophage Polarization via AMP-activated Protein Kinase (AMPK). J Biol Chem (2015) 290:16979-88. doi: 10.1074/jbc.M115.646992

72. Vijayakumar A, Aryal P, Wen J, Syed I, Vazirani RP, Moraes-Vieira PM, et al. Absence of Carbohydrate Response Element Binding Protein in Adipocytes Causes Systemic Insulin Resistance and Impairs Glucose Transport. Cell Rep (2017) 21:1021-35. doi: 10.1016/j.celrep.2017.09.091

73. Summers SA, Chaurasia B, Holland WL. Metabolic Messengers: ceramides. Nat Metab (2019) 1:1051-8. doi: 10.1038/s42255-019-0134-8

74. Shin KC, Hwang I, Choe SS, Park J, Ji Y, Kim JI, et al. Macrophage VLDLR mediates obesity-induced insulin resistance with adipose tissue inflammation. Nat Commun (2017) 8:1087. doi: 10.1038/s41467-01701232-w

75. Chaurasia B, Talbot CL, Summers SA. Adipocyte Ceramides-The Nexus of Inflammation and Metabolic Disease. Front Immunol (2020) 11:576347. doi: 10.3389/fimmu.2020.576347

76. Kahn BB, Flier JS. Obesity and insulin resistance. J Clin Invest (2000) 106:473-81. doi: 10.1172/JCI10842
77. Savage DB. Mouse models of inherited lipodystrophy. Dis Model Mech (2009) 2:554-62. doi: 10.1242/dmm.002907

78. Huang-Doran I, Sleigh A, Rochford JJ, O’Rahilly S, Savage DB. Lipodystrophy: metabolic insights from a rare disorder. J Endocrinol (2010) 207:245-55. doi: 10.1677/JOE-10-0272

79. Donath MY, Shoelson SE. Type 2 diabetes as an inflammatory disease. Nat Rev Immunol (2011) 11:98-107. doi: 10.1038/nri2925

80. Johnson JA, Albu JB, Engelson ES, Fried SK, Inada Y, Ionescu G, et al. Increased systemic and adipose tissue cytokines in patients with HIVassociated lipodystrophy. Am J Physiol Endocrinol Metab (2004) 286: E261-71. doi: 10.1152/ajpendo.00056.2003

81. Lagathu C, Eustace B, Prot M, Frantz D, Gu Y, Bastard JP, et al. Some HIV antiretrovirals increase oxidative stress and alter chemokine, cytokine or adiponectin production in human adipocytes and macrophages. Antivir Ther (2007) 12:489-500.

82. Shimomura I, Hammer RE, Richardson JA, Ikemoto S, Bashmakov Y, Goldstein JL, et al. Insulin resistance and diabetes mellitus in transgenic mice expressing nuclear SREBP-1c in adipose tissue: model for congenital generalized lipodystrophy. Genes Dev (1998) 12:3182-94. doi: 10.1101/ gad.12.20.3182

83. Herrero L, Shapiro H, Nayer A, Lee J, Shoelson SE. Inflammation and adipose tissue macrophages in lipodystrophic mice. Proc Natl Acad Sci U S A (2010) 107:240-5. doi: 10.1073/pnas.0905310107

84. Martin S, Fernandez-Rojo MA, Stanley AC, Bastiani M, Okano S, Nixon SJ, et al. Caveolin-1 deficiency leads to increased susceptibility to cell death and fibrosis in white adipose tissue: characterization of a lipodystrophic model. PloS One (2012) 7:e46242. doi: 10.1371/journal.pone.0046242

85. Gandotra S, Le Dour C, Bottomley W, Cervera P, Giral P, Reznik Y, et al. Perilipin deficiency and autosomal dominant partial lipodystrophy. $N$ Engl $J$ Med (2011) 364:740-8. doi: 10.1056/NEJMoa1007487

86. Wang Q, Wu H. T Cells in Adipose Tissue: Critical Players in Immunometabolism. Front Immunol (2018) 9:2509. doi: 10.3389/ fimmu.2018.02509

87. Jaitin DA, Adlung L, Thaiss CA, Weiner A, Li B, Descamps H, et al. LipidAssociated Macrophages Control Metabolic Homeostasis in a Trem2Dependent Manner. Cell (2019) 178:686-98.e14. doi: 10.1016/ j.cell.2019.05.054

88. Camell CD, Sander J, Spadaro O, Lee A, Nguyen KY, Wing A, et al. Inflammasome-driven catecholamine catabolism in macrophages blunts lipolysis during ageing. Nature (2017) 550:119-23. doi: 10.1038/nature24022

89. Camell CD, Gunther P, Lee A, Goldberg EL, Spadaro O, Youm YH, et al. Aging Induces an Nlrp3 Inflammasome-Dependent Expansion of Adipose B Cells That Impairs Metabolic Homeostasis. Cell Metab (2019) 30:102439.e6. doi: 10.1016/j.cmet.2019.10.006

90. Gao H, Arner P, Beauchef G, Guere C, Vie K, Dahlman I, et al. Age-Induced Reduction in Human Lipolysis: A Potential Role for Adipocyte Noradrenaline Degradation. Cell Metab (2020) 32:1-3. doi: 10.1016/ j.cmet.2020.06.007

91. Ferrero R, Rainer P, Deplancke B. Toward a Consensus View of Mammalian Adipocyte Stem and Progenitor Cell Heterogeneity. Trends Cell Biol (2020) 30:937-50. doi: 10.1016/j.tcb.2020.09.007

92. Ghaben AL, Scherer PE. Adipogenesis and metabolic health. Nat Rev Mol Cell Biol (2019) 20:242-58. doi: 10.1038/s41580-018-0093-Z

93. Vishvanath L, Gupta RK. Contribution of adipogenesis to healthy adipose tissue expansion in obesity. J Clin Invest (2019) 129:4022-31. doi: 10.1172/ JCI129191

94. Schwalie PC, Dong H, Zachara M, Russeil J, Alpern D, Akchiche N, et al. A stromal cell population that inhibits adipogenesis in mammalian fat depots. Nature (2018) 559:103-8. doi: 10.1038/s41586-018-0226-8

95. Burl RB, Ramseyer VD, Rondini EA, Pique-Regi R, Lee YH, Granneman JG. Deconstructing Adipogenesis Induced by beta3-Adrenergic Receptor Activation with Single-Cell Expression Profiling. Cell Metab (2018) 28:300-9.e4. doi: 10.1016/j.cmet.2018.05.025

96. Ceccarelli S, Pontecorvi P, Anastasiadou E, Napoli C, Marchese C. Immunomodulatory Effect of Adipose-Derived Stem Cells: The Cutting Edge of Clinical Application. Front Cell Dev Biol (2020) 8:236. doi: 10.3389/ fcell.2020.00236 
97. Li P, Guo X. A review: therapeutic potential of adipose-derived stem cells in cutaneous wound healing and regeneration. Stem Cell Res Ther (2018) 9:302. doi: 10.1186/s13287-018-1044-5

98. Hepler C, Shan B, Zhang Q, Henry GH, Shao M, Vishvanath L, et al. Identification of functionally distinct fibro-inflammatory and adipogenic stromal subpopulations in visceral adipose tissue of adult mice. Elife (2018) 7:e39636. doi: 10.7554/eLife.39636

99. Marcelin G, Ferreira A, Liu Y, Atlan M, Aron-Wisnewsky J, Pelloux V, et al. A PDGFR $\alpha$-Mediated Switch toward CD9(high) Adipocyte Progenitors Controls Obesity-Induced Adipose Tissue Fibrosis. Cell Metab (2017) 25:673-85. doi: 10.1016/j.cmet.2017.01.010

100. Shan B, Shao M, Zhang Q, Hepler C, Paschoal VA, Barnes SD, et al. Perivascular mesenchymal cells control adipose-tissue macrophage accrual in obesity. Nat Metab (2020) 2:1332-49. doi: 10.1038/s42255-020-00301-7

101. Jackson-Jones LH, Smith P, Portman JR, Magalhaes MS, Mylonas KJ, Vermeren MM, et al. Stromal Cells Covering Omental Fat-Associated Lymphoid Clusters Trigger Formation of Neutrophil Aggregates to Capture Peritoneal Contaminants. Immunity (2020) 52:700-15.e6. doi: 10.1016/j.immuni.2020.03.011

102. Spallanzani RG, Zemmour D, Xiao T, Jayewickreme T, Li C, Bryce PJ, et al. Distinct immunocyte-promoting and adipocyte-generating stromal components coordinate adipose tissue immune and metabolic tenors. Sci Immunol (2019) 4(35):eaaw3658. doi: 10.1126/sciimmunol.aaw3658

103. Hwang I, Jo K, Shin KC, Kim JI, Ji Y, Park YJ, et al. GABA-stimulated adipose-derived stem cells suppress subcutaneous adipose inflammation in obesity. Proc Natl Acad Sci (2019) 116:11936. doi: 10.1073/pnas.1822067116
104. Hwang I, Kim JB. Two Faces of White Adipose Tissue with Heterogeneous Adipogenic Progenitors. Diabetes Metab J (2019) 43:752-62. doi: 10.4093/ dmj.2019.0174

105. Vijay J, Gauthier MF, Biswell RL, Louiselle DA, Johnston JJ, Cheung WA, et al. Single-cell analysis of human adipose tissue identifies depot and disease specific cell types. Nat Metab (2020) 2:97-109. doi: 10.1038/s42255-019-0152-6

106. Sun W, Dong H, Balaz M, Slyper M, Drokhlyansky E, Colleluori G, et al. snRNA-seq reveals a subpopulation of adipocytes that regulates thermogenesis. Nature (2020) 587:98-102. doi: 10.1038/s41586-020-2856-x

107. Henriques F, Bedard AH, Guilherme A, Kelly M, Chi J, Zhang P, et al. Single-Cell RNA Profiling Reveals Adipocyte to Macrophage Signaling Sufficient to Enhance Thermogenesis. Cell Rep (2020) 32:107998. doi: 10.1016/j.celrep.2020.107998

108. Deutsch A, Feng D, Pessin JE, Shinoda K. The Impact of Single-Cell Genomics on Adipose Tissue Research. Int J Mol Sci (2020) 21(13):4773. doi: $10.3390 /$ ijms 21134773

Conflict of Interest: The authors declare that the research was conducted in the absence of any commercial or financial relationships that could be construed as a potential conflict of interest.

Copyright (C) 2021 Park, Sohn, Han, Park, Huh, Choe and Kim. This is an open-access article distributed under the terms of the Creative Commons Attribution License (CC BY). The use, distribution or reproduction in other forums is permitted, provided the original author(s) and the copyright owner(s) are credited and that the original publication in this journal is cited, in accordance with accepted academic practice. No use, distribution or reproduction is permitted which does not comply with these terms. 